\title{
A eletricidade no Brasil sob a perspectiva da história social
}

\author{
Electricity in Brazil in a social history perspective
}

\author{
Verônica Pimenta Velloso \\ Historiadora do Departamento de Pesquisa da \\ Casa de Oswaldo Cruz/Fiocruz \\ veropim@coc.fiocruz.br
}

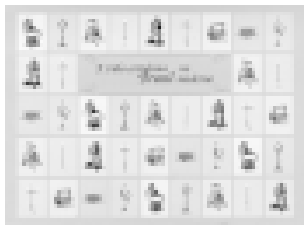

A vida cotidiana no Brasil moderno: a energia elétrica e a sociedade brasileira (1880-1930)

Rio de Janeiro, Centro de Memória da Eletricidade no Brasil, 2001, 273p.
$\mathrm{O}$ Centro de Memória da Eletricidade no Brasil, criado em 1986 com o objetivo de promover a preservação do patrimônio histórico da energia elétrica no Brasil, dedica-se, entre outras atividades, à produção de uma historiografia voltada para a compreensão do processo de implantação da energia elétrica e de seu desenvolvimento no país. Essa produção tem chamado a atenção pela qualidade em termos de informações iconográficas e textuais sobre o tema; citando como exemplos mais recentes: Cidade em movimento: energia elétrica e meios de transporte na cidade do Rio de Janeiro (2001); Energia elétrica no Brasil - 500 anos (2000); e Reflexos da cidade: a iluminação pública na cidade do Rio de Janeiro (1565-1930) (1999).

Em outubro de 2001, comemorando o seu 15ㅇ aniversário, a instituição lançou A vida cotidiana no Brasil moderno: a energia elétrica e a sociedade brasileira (1880-1930). Esse último lançamento realizado "no apagar das luzes", num momento em que a ordem do dia era o racionamento de energia elétrica como conseqüência da crise no setor, explicita a atualidade do tema. Vale ressaltar a formação da equipe de autores da obra, constituída em grande parte por historiadores e museólogos.

A divisão da obra em três capítulos, intitulados 'Modernidade e progresso', 'A cidade', e 'A casa', foi orientada pela preocupação em construir o contexto histórico-social do período em que os efeitos da utilização da energia elétrica se fizeram sentir no cotidiano dos principais centros urbanos da sociedade brasileira. Dentro dessa perspectiva, são analisados os aspectos do cotidiano que abrangem os espaços público e privado, os hábitos e práticas sociais relacionados à vida material, e a relação entre a produção e o consumo de objetos.

O primeiro capítulo introduz o leitor no cenário da modernidade que se anuncia mundialmente a partir de finais do século XIX, com as transformações científico-tecnológicas promovidas em decorrência da chamada segunda revolução industrial, quando foram criadas novas formas e fontes de produção de energia. A eletricidade aí, como nova tecnologia, seria uma das formas de manifestação dessa modernidade, sendo compreendida no contexto de transformações sociais do período, entre as quais se situa o avanço da ciência na Europa, como desdobramento das descobertas científicas, que vinham sendo realizadas desde o século XVIII, especialmente na área da física. Sob esta ótica, no limiar do século $\mathrm{XX}$, o desenvolvimento da indústria de energia elétrica é visto como 
fruto de investigações científicas neste campo do conhecimento. Ou seja, tecnologia e ciência, descoberta e pesquisa científicas são apresentadas inter-relacionadas com as questões sociais nesse estudo.

Diante dos dois ramos distintos seguidos pela indústria do setor elétrico - um voltado para a produção e distribuição de energia, e outro, dedicado à produção de equipamentos e aparelhos elétricos —, considera-se que a capacidade geradora de energia elétrica passou a ser um indicador do grau de desenvolvimento econômico de uma sociedade, do seu crescimento urbano e industrial. Por outro lado, através do consumo dos produtos dessa indústria de eletrotécnicos, que se firmavam como um dos compositores do cenário da vida moderna, compreende-se que os setores médios urbanos tinham a oportunidade de vivenciar o avanço da ciência. As exposições nacionais e internacionais, realizadas entre os séculos XIX e XX, são apontadas aqui também como divulgadoras das conquistas científicas do período, explorando o fetiche das mercadorias e traduzindo o surgimento de novos bens de consumo e padrões de conforto, onde a eletricidade ocupou lugar de destaque.

$\mathrm{Na}$ construção do pano de fundo sobre o qual se inseriu o setor de energia elétrica no Brasil, situando-o no contexto mundial, é apresentado um histórico sobre a instalação das primeiras usinas geradoras de energia elétrica de origem térmica e hidráulica no país. Nesse panorama, a criação do sistema de concessões a empresas particulares para explorar o setor elétrico no país é explicado pela falta de recursos por parte das autoridades públicas para suprir as necessidades de energia elétrica advindas da expansão do setor industrial e de serviços, incluindo a modernização dos principais centros urbanos. Com a injeção de capitais estrangeiros, através da fundação da The São Paulo Tramway, Light and Power Company Ltd. (1899) e da The Rio de Janeiro Tramway, Light and Power Company Ltd. (1904), o parque de usinas geradoras de energia elétrica foi ampliado, promovendo a eletrificação do sistema de transportes coletivos e da iluminação pública nessas capitais brasileiras. O texto segue relacionando e indicando o ano da implantação do sistema de iluminação elétrica das ruas em algumas cidades do interior dos estados e em outras capitais.

A cidade como espaço onde a modernidade e o progresso deveriam ser implementados é tema e título do segundo capítulo. A discussão sobre a mudança do significado de público e privado é introduzida a partir da citação do trecho de uma crônica de autoria de Paulo Barreto (João do Rio), atribuído erroneamente a Lima Barreto: "Os séculos passam, deslizam, levando as coisas fúteis e os acontecimentos notáveis. Só persiste e fica, legado das gerações cada vez maior, o amor da rua" (p. 74). ${ }^{1}$ A rua da cidade como espaço público adquire aí um sentido especial, evidenciando-se. A noção de espaço público se amplia, extrapolando a esfera política, e passa a ser identificado com o espaço urbano.

\footnotetext{
${ }^{1}$ Essa crônica, intitulada 'A rua', integra a obra A alma encantadora das ruas, editada pela Garnier em 1908, que reuniu uma série de reportagens de autoria de João do Rio publicadas inicialmente no jornal Gazeta de Notícias e na revista Kosmos, entre os anos de 1903 e 1906, tratando sobre a vida urbana, a fisionomia das ruas e as profissões citadinas na cidade do Rio de Janeiro. Depois disso, houve outras edições da obra. Ver João do Rio (Paulo Barreto), A alma encantadora das ruas, Rio de Janeiro, Organizações Simões, 1951, p. 9. Na década de 1990, foi reeditada pela Prefeitura da Cidade do Rio de Janeiro.
} 
Portanto, esse capítulo vem dar visualidade à paisagem urbana. A cidade que se moderniza segundo os moldes europeus, sofrendo reformas que promovem obras de saneamento, embelezamento, iluminação e verticalização, dando origem aos primeiros arranha-céus. Aqui são dadas informações específicas sobre a implantação dos serviços movidos a energia elétrica, correspondentes a cada uma das capitais brasileiras: além de Rio de Janeiro e São Paulo, foram abordadas nesse estudo Belo Horizonte, Salvador, Curitiba, Porto Alegre, Recife, Belém e Manaus. Nesse panorama, são enfatizados os temas sobre transporte, trabalho e saúde.

Merece destaque a parte referente à saúde, na qual é analisado o impacto da ampliação da utilização da energia elétrica nos serviços de saúde, a partir do surgimento de diversos aparelhos elétricos de uso terapêutico para doenças mentais, alcoolismo, entre outras enfermidades.

O espaço privado da casa é tratado no terceiro e último capítulo, fazendo um contraponto com o espaço público ou mesmo numa relação interativa com este. A partir das transformações ocorridas entre os séculos XIX e XX, compreende-se que as relações entre a casa e a rua também se modificaram. O espaço doméstico moderno adquiriu noções de privacidade e conforto, alterando a arquitetura da casa, espelhada na nova divisão dos cômodos que confere privacidade a cada um dos seus habitantes que constituem ou que dão a idéia de uma familia nuclear, oriunda dos setores burgueses.

O contraste dessas residências burguesas com as moradias dos setores populares é bem explorado através do texto imagético, explicitando a questão da exclusão social no acesso à privacidade e ao conforto, incluindo os serviços movidos a energia elétrica. Diferentemente, as melhorias urbanas empreendidas no espaço público da rua, tais como a iluminação elétrica, são de certa forma socializadas pelos diversos grupos sociais.

A reprodução de uma charge de Raul Pederneiras, retratando o interior de uma casa de cômodos do período, mostra a precariedade desse tipo de habitação popular. Em contraposição, outras imagens nos mostram desenhos, plantas e fotografias tanto do exterior como do interior das casas consideradas modernas na época, nas quais aparecem as duas opções de iluminação (elétrica e a gás), imagens separadas dos vários cômodos que deveriam compor uma casa, dando destaque ao banheiro e à cozinha. Nesses últimos, é chamada a atenção para as mudanças significativas por que passaram, a partir da incorporação de novos hábitos de limpeza e higiene.

Assinalam-se também os hábitos domésticos noturnos que se criam a partir da instalação da iluminação elétrica no interior das casas modernas e do surgimento do fonógrafo e do rádio, tais como leituras, reuniões de família, ampliando-se as atividades de lazer no lar. Os aparelhos eletrodomésticos que surgem em função do desenvolvimento da indústria eletrotécnica (geladeira, ferro de passar roupa, aspirador de pó, ventilador, fogões elétricos, entre outros) também são citados como transformadores do cenário da casa, tornando-o progressivamente mais mecanizado. A casa deixa de ser um local de trabalho, tornando-se lugar de intimidade e isolamento, no qual a palavra conforto ganha uma nova conotação: de busca do bem-estar material e não mais de "consolação" e "ajuda". Em 
contrapartida, as habitações populares passaram a ser alvo das campanhas sanitárias promovidas a partir de finais do século XIX, quando eram apontadas como focos das epidemias e doenças que acometiam as populações dos centros urbanos.

Ao finalizarmos a leitura desse estudo, percebemos que prevaleceu uma abordagem histórica, não-linear, pontuando sobre apropriações diversas da energia elétrica que variam de acordo com os setores urbanos (trabalho, saúde e transporte) ou com os grupos sociais consumidores dos seus serviços (populares e burgueses) relacionados aos espaços público e privado. Uma história que dialoga e se articula com outros ramos do conhecimento, tais como a sociologia, a arquitetura e a economia.

A bibliografia consultada para elaboração da obra demonstra atualidade e confirma a intenção de apresentar uma abordagem multidisciplinar do tema. Na área específica da história da eletricidade, foi pesquisada tanto a historiografia de origem internacional (francesa, inglesa e italiana), como trabalhos acadêmicos brasileiros recentes. A diversificação dos tipos de fontes utilizadas foi acrescida de relatórios de ministérios (da Agricultura, Indústria e Comércio; da Fazenda; da Indústria, Viação e Obras Públicas), periódicos e páginas eletrônicas.

Em termos da iconografia utilizada constatamos a edição de mais um belo e rico trabalho pelo Centro de Memória da Eletricidade no Brasil. Em cada um dos capítulos, a parte escrita é enriquecida com o texto imagético contido nas gravuras, desenhos, mapas, plantas, pinturas, cartões-postais e fotografias. A indicação dos créditos correspondentes a cada uma dessas imagens, no final do livro, nos revela uma pesquisa bastante apurada e rica através do uso de fontes diversas, tais como periódicos nacionais e estrangeiros, explorando principalmente as charges e caricaturas; catálogos de museus internacionais ligados ao setor elétrico, e álbuns. Essa documentação é constituinte de coleções particulares e de acervos de várias instituições ligadas ao setor elétrico, como o próprio Centro de Memória da Eletricidade.

A seleção de fragmentos de textos literários de época, utilizados no início dos capítulos ou para introduzir novo assunto dentro de cada um deles, estimula a leitura do texto escrito e das imagens. Esses textos são de autoria variada, destacando-se entre eles Mário de Andrade, Olavo Bilac, João do Rio, Lima Barreto, Júlio Ribeiro, o que nos permite visualizar através de seus olhares a época estudada. Faltou, no entanto, mais atenção na identificação dos nomes dos autores, o que teria evitado erros como o já mencionado entre Paulo Barreto (João do Rio) e Lima Barreto. A semelhança entre os nomes talvez tenha sido o motivo da confusão. Da mesma forma, a apresentação da Exposição Nacional de 1908 como uma exposição internacional (p. 59) poderia ter sido evitada. Aqui, mais uma vez faltou atenção, pois nas páginas anteriores o erro não ocorreu, como podemos observar na legenda de um cartão-postal que a retratou (p. 18).

A vida cotidiana no Brasil moderno: a energia elétrica e a sociedade brasileira (1880-1930) afirma-se como uma obra de referência para o tema da eletricidade no Brasil, não podendo deixar de ser consultado por quem se dedica ou que venha a se dedicar a estudos dessa matéria. 
A ELETRICIDADE NO BRASIL

Numa linguagem simples e muito bem articulada, o texto instiga o leitor, mesmo que seja leigo, a conhecer o assunto. Assim, ao conferir um sentido social amplo à história da eletricidade, fornece instrumentos para um público leitor extenso refletir sobre o processo de construção da importância do setor elétrico para a sociedade em geral, sob o ponto de vista econômico, cultural, científico e político. 